\title{
The influence of different oxidation processes on micron-sized aluminum particles
}

\author{
Liu Yang, Ren Hui, Jiao Qingjie* \\ State Key Laboratory of Explosive Science and Technology, School of Mechatronical Engineering, \\ Beijing Institute of Technology, No.5 Zhongguancun South Street, Haidian District, Beijing, 100081, \\ People's Republic of China. \\ Liuyang19881225@126.com, huiren@bit.edu.cn, jqj.bit@gmail.com.
}

\begin{abstract}
KEYWORDS: aluminum particles, oxidation mechanism, Differential scanning calorimetry.
ABSTRACT. The objective of this work is to investigate experimentally the oxidation behavior of micron-sized aluminum particles with controlled thickness of alumina passive layers in oxidized environment. Samples in four different sizes were studied using differential scanning calorimetry, thermogravimetry analysis and mass spectrometry (DSC-TGA-MS). Oxidation process of aluminum particles can be divided into four stages and partially oxidized samples of specific stages were collected then analyzed by X-ray diffraction (XRD), scanning electron microscope (SEM) and transmission electron microscopy (TEM). Oxidation rates of micron-sized aluminum particles are affected by the gas byproducts during the main reaction period. The thickness of alumina layer outside aluminum particles were thickened by controlling the heating process and the results of identical heating process demonstrated that alumina passive layer has a clear restriction on the oxidation process. The thicker of the alumina shell is, the harder the mass diffusion is going through. In this gradually heating system, oxidation of aluminum particles at low temperatures range is dominated by diffusion of ions on both sides of alumina shell, whereas the reaction at higher temperature is controlled by kinetics. When the alumina shell was manually treated to a thicker degree, the oxidation process of micron-sized aluminum particles can be totally suspended.
\end{abstract}

\section{INTRODUCTION}

Aluminum particles are often added into various energetic materials, including pyrotechnics, explosives, and rocket propellants ${ }^{1-2}$. Because of its several practical applications in energetic materials, metal combustion process, especially aluminum combustion process is a continuing interest of a lot of researchers. The performance of energetic materials can be highly improved with the addition of aluminum particles, such as oxidation enthalpy, combustion temperature and motor acoustic stability. In recent several decades, basic understanding of oxidation mechanism about aluminum particles in different conditions has been improved significantly according to experimental and theoretical investigations $^{3-4}$. A. RAI believes that the oxidation of aluminum nanoparticles occurs in two regimes based on their experimental evidence ${ }^{5}$, while Edward. L. Dreizin reported that the combustion of uniform micron-sized aluminum particles in air revealed three distinct ${ }^{6}$ histories. There are also some results on sub-micron-sized aluminum particles which provide us different possible reaction models based on shrinking-core model ${ }^{7}$. There is a strong thermodynamic driving force for the reaction of aluminum with various oxidizers such as air, water vapor and carbon dioxide, but aluminum ignition difficulties and application limitations occur as a result of the initial oxide layer that coats each particle, separating the metal fuel from the oxidizing gases ${ }^{8}$. When aluminum burns in a composite solid propellant, the aluminum typically reacts with combustion products of the energetic oxidizer and binder, such as $\mathrm{H}_{2} \mathrm{O}$ and $\mathrm{CO}_{2}{ }^{9}$, for this reason, it is meaningful to find out the oxidation behavior of aluminum powders in $\mathrm{CO}_{2}{ }^{10}$. Although a series of oxidation mechanism has been built by researchers about the 
changing of aluminum oxide layers in different conditions, the oxidation mechanism of aluminum particles is still not that clear. How the thickness of alumina passive layer influences the general oxidation of aluminum particle is not known comprehensively. Thermal analysis is widely used as a method which is mature enough to provide useful information on phase transitions and oxidation kinetics through exothermic and endothermic reactions ${ }^{11}$. In order to find out the oxidation mechanism of aluminum particles with different thickness of oxide layers, thermal analysis along with the supporting characterization including mass spectra (MS), X-ray diffraction (XRD), scanning electron microscope (SEM) were used in the research, the oxidation process can be deeply understood.

In this paper, oxidation mechanism is investigated on micron-sized spherical aluminum particles which are coated with natural amorphous and treated by different methods aluminum oxide. An oxidation history which is accounted for multiple processes occurring in aluminum oxidation is not expected to be limited to quasi-steady description of the single aluminum particle oxidizing process in gradually heated oxidizing atmosphere was developed. In order to establish correlations between the structural parameters and the reactivity of the powders, it is also important to identify the mechanisms at the scale of a single particle and to understand the growing evolution of alumina layers ${ }^{12}$. Therefore, the thickness of alumina film was changed in this study and the influence caused by the increasing thickness of alumina layers during the oxidation was proved.

\section{EXPERIMENTAL SECTION}

\section{Materials}

Four samples from $\mathrm{Al} \# 1$ to $\mathrm{Al} \# 4$ produced by Angang Group Aluminum Powder Co., Ltd were used in the experiment. In order to clarify the microscopic morphology of aluminum particles, all the samples were characterized by HITACHI S4700 SEM. SEM images (Fig. 1) present that aluminum particles were ideal spherical, the surface of each particle was not completely smooth just as the previous report ${ }^{13}$. There is no agglomeration for the original powders as well.

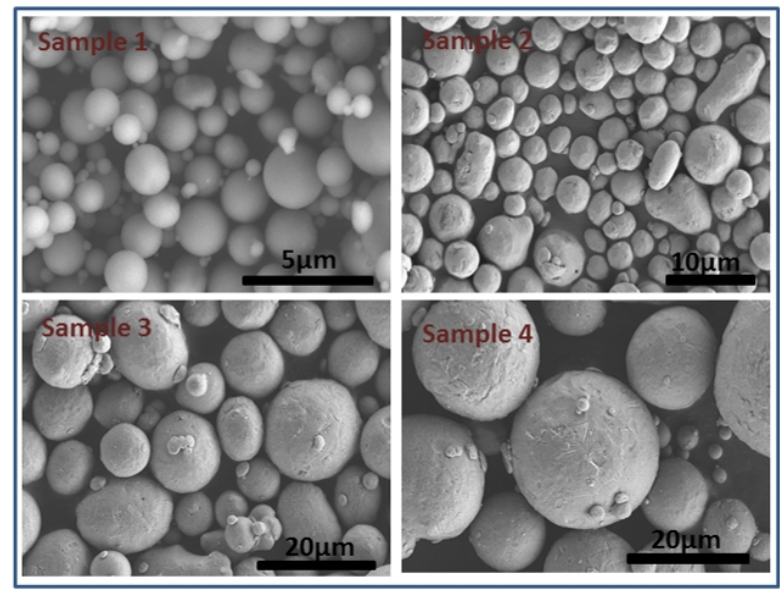

Fig. 1 SEM images of different aluminum samples.

The size and distribution of all the samples was measured by means of Malvern Mastersizer 2000 laser particle size analyzer for further characterization. The median diameter (D50) of four samples and the fitting curves of size distribution computing by statistical methods are reported in Table 1 . The particle size distribution of aluminum samples is in line with the lognormal distribution according to Kolmogorov test curve fitting test which has a correlation better than $96 \%$. 
Table 1 Size distribution and fitting curves of aluminum samples.

\begin{tabular}{|c|c|c|c|}
\hline Sample & D50/um & Sample & D50/um \\
\hline Sample 1 & 1.76 & Sample 2 & 5.24 \\
\hline Sample 3 & 13.35 & Sample 4 & 24.02 \\
\hline $\begin{array}{l}\text { Fitting } \\
\text { curve }\end{array}$ & $f(x)=\frac{A}{\sqrt{2 \pi}}$ & $\frac{(\mathrm{n} \pi-\mu)^{2}}{2 a^{2}}$ & $\mathrm{x} \in[\mathrm{a}, \mathrm{b}]$ \\
\hline
\end{tabular}

\section{Thermal analysis}

Oxidation of aluminum particles at elevated temperatures were studied by the combination of NETZSCH STA449F3 - DSC200F3 Thermo-Gravimetric Analyzer - Differential Scanning Calorimeter and Mass spectrometry (TGA-DSC-MS). These facilities can closely record the residence time, temperature histories in different oxidation environment allowing for a variety of solid-solid, solidliquid, solid-gas, liquid-gas interactions. All the samples were heated from room temperature to $1450^{\circ} \mathrm{C}$ in thermal analysis experimental process. The balance and furnace were purged with argon at 0.6 and $1.2 \mathrm{~L} / \mathrm{h}$ respectively. The heating rate was $20^{\circ} \mathrm{C} / \mathrm{min}$, this heating rate was appropriate to ensure a high resolution of mass and energy variations as a function of temperature and control measurement error. Reaction chamber was vacuumed prior to introducing research grade $\mathrm{CO}_{2}$ and $\mathrm{O}_{2}$, which was kept at a steady flow rate of about $1.2 \mathrm{~L} / \mathrm{h}$. This flow rate of gas was more than enough and all the samples could react completely. Gas flow rate was kept constant in order to make the sample chamber an atmospheric pressure. The amount of aluminum powders in each cycle was $5 \mathrm{mg}$ and all evenly distributed inside the standard alumina crucible. In order that the experiments were repeatable and accidental error was eliminated, all experiments were repeated third times.

\section{RESULTS AND DISCUSSION}

Thermal behavior of micron-sized aluminum particles.
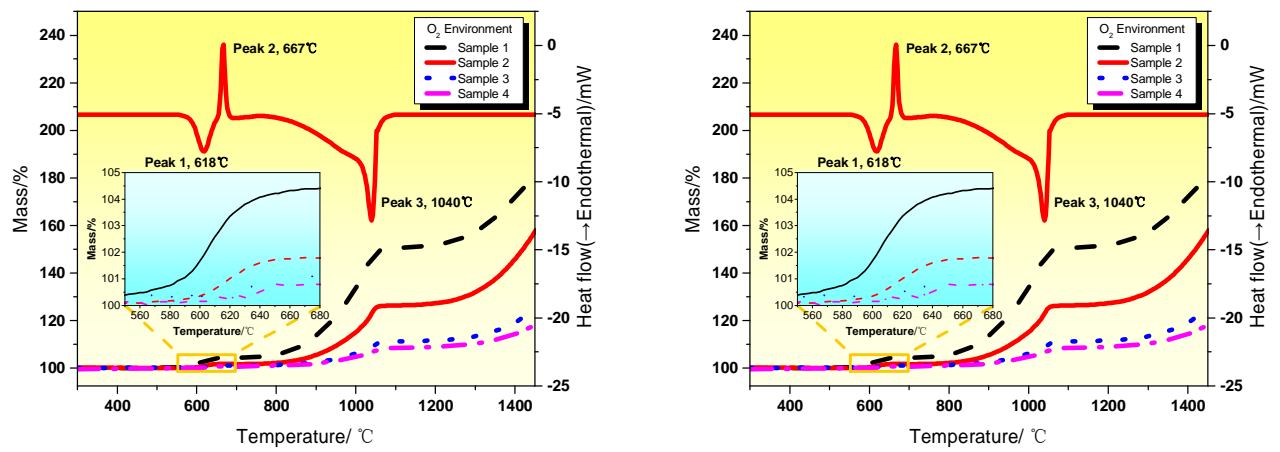

Fig. 2 TG curves of four aluminum samples and DSC curve of sample 2 in oxygen and carbon dioxide environments.

From the TG-DSC curves of aluminum particles which is shown in Fig. 2, the oxidation process can be divided into four stages both in $\mathrm{CO}_{2}$ and $\mathrm{O}_{2}$ environment. In the first stage, from room temperature to $600^{\circ} \mathrm{C}$, slightly oxidation occurred with the generation of carbon. This process was corresponded to a small exothermic period. Then aluminum melted in the second stage with an obvious endothermic peak. Stage III is from $700^{\circ} \mathrm{C}$ to $1130^{\circ} \mathrm{C}$ in carbon dioxide, while is from $700^{\circ} \mathrm{C}$ to $1050^{\circ} \mathrm{C}$ in oxygen. Liquid aluminum was oxidized by gas around. Stage IV, from $1150^{\circ} \mathrm{C}$ to a higher degree, the specific processes responsible for the individual oxidation stages of aluminum powders must be 
understood in order to accurately model aluminum ignition. The oxidation stages observed in this work are generally consistent with previous reports on aluminum powder oxidation.
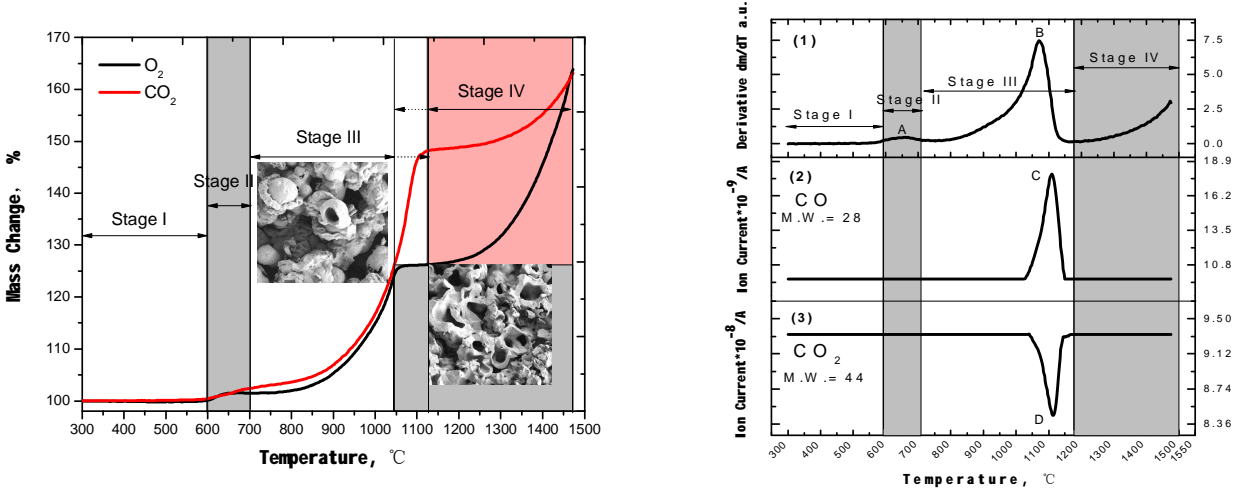

Fig. 3 Al\#2 TG trace recorded of Fig. 4 (1)DTG curve of $\mathrm{Al \# 2}$ in $\mathrm{CO}_{2}$; (2) MS spectrum aluminum oxidation in $\mathrm{O}_{2}$ and $\mathrm{CO}_{2}$. characteristic of $\mathrm{CO}$; (3) MS spectrum characteristic of $\mathrm{CO}_{2}$.

Intermediate and final products were collected and analyzed by XRD and SEM. In order to collect intermediate products of each stage without any other impact, reaction was stopped at certain temperature, at the same time, argon was purged in immediately until samples cooled down to room temperature. TG-DSC was combined with MS which can measure gas products during oxidation including $\mathrm{O}_{2}, \mathrm{CO}, \mathrm{CO}_{2}, \mathrm{C}_{2} \mathrm{O}$ etc. There is a clear difference in the third stage of oxidation process in two atmospheres. The main difference appeared that gas byproduct only generated in $\mathrm{CO}_{2}$ environment. The mass increasing in $\mathrm{O}_{2}$ was $20 \%$ higher than that in $\mathrm{CO}_{2}$ during the third stage. React rate in the first half of experiment between two kinds of gas was almost same. The diffusion was controlled by the alumina shell. However, the generation of $\mathrm{CO}$ in the third stage in $\mathrm{CO}_{2}$ oxidation environment had a great contribute to the oxidation. In the oxygen environment, no gas product was emerged during heating. SEM illustrated that reaction was controlled by outwards diffusion. Therefore, most particles were stick together.

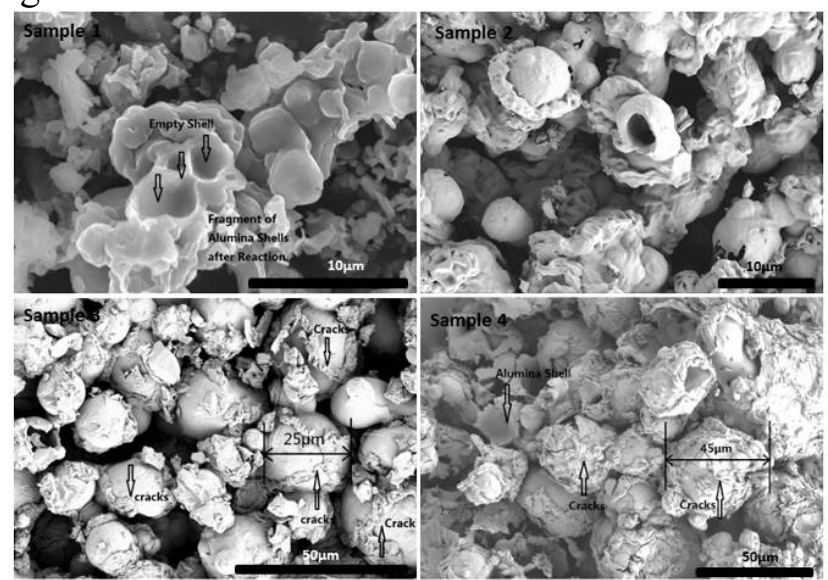

Fig. 5 Monograph of aluminum particles heated from room temperature to $1450^{\circ} \mathrm{C}$

Fig. 5 presents the final products in the experiments from Al\#1 to Al\#4. Some hollow shell structure and a lot of integral spherical shells which were shrunk a lot could be seen. The bigger samples were still roughly sphere with some cracks on the surface. Outwards diffusion of liquid aluminum inside the alumina shell was not uniform across the surface. It started at the weak position where several cracks appeared on the surface. The structure and characteristic of alumina shell could be changed with the evolving of alumina shell from amorphous phase to $\gamma-\mathrm{Al}_{2} \mathrm{O}_{3}$ and $\alpha-\mathrm{Al}_{2} \mathrm{O}_{3}$. Small 
particles could be oxidized completely and the reaction products consist of fragment of alumina shell of aluminum particles. When it comes to the larger sized powders $(>10 \mu \mathrm{m})$, the sphere particles with a few cracks on the surface could be seen instead of empty shell structure. SEM observations after DSC scans prove that the granular structure of the powder was modified by the thermal treatment. It is noted that if the molten aluminum is pushed into these cracks by the high internal pressure characteristic of the stress field, its surface, where reaction occurs, could be fractal in nature and affect the fundamental nature of the burning law.
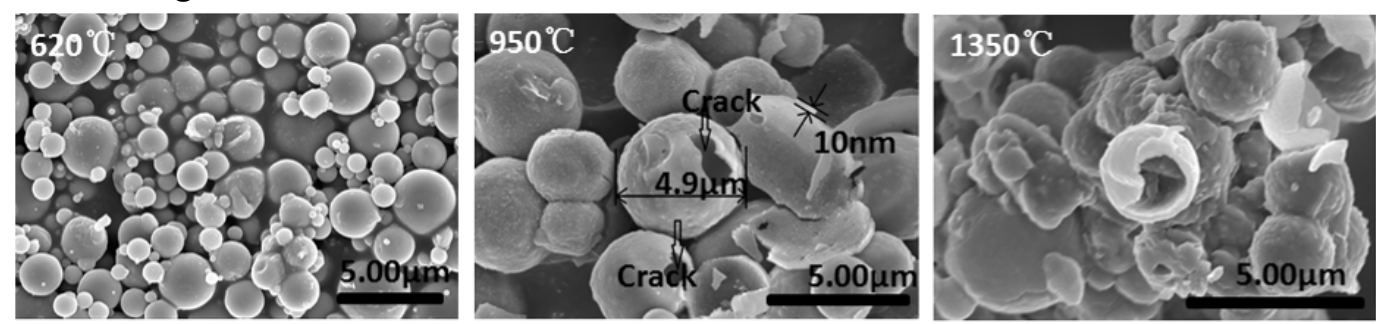

Fig. 6 SEM images of Al\#2 collected from different temperature.

Fig. 6 is the SEM pictures of Al\#2 collected after heating to different temperature, we could intuitionally get an overview of all relevant monograph with size and thickness of alumina shell representing their oxidation rates. Compared with Fig. 1, particles heated to $620^{\circ} \mathrm{C}$ changed very little on sphere shape and surface condition, however, clear hollow aluminum particles were observed and the thickness of alumina shell belongs to some completely oxidized particles can be roughly measured as $0.1 \mu \mathrm{m}$ in monograph of $\mathrm{Al} \# 2$ heated to different temperature.

In order to find out the difference of oxidation process in between four stages and also to identify intermediate oxidation products, all the samples were heated to $620^{\circ} \mathrm{C}, 950^{\circ} \mathrm{C}$ and $1350^{\circ} \mathrm{C}$ in the same condition. Intermediate products were collected and analyzed by XRD as well. X-ray pattern of Al\#2 heated to different temperatures was provided by Fig. 7. Amorphous alumina firstly transformed into a denser $\gamma-\mathrm{Al}_{2} \mathrm{O}_{3}$ polymorph with the elevation of temperature. This phase transformation could reduce currency compactness and the diffusion resistance of the oxide layers. Peaks of carbon were found in $620^{\circ} \mathrm{C} \mathrm{XRD} \mathrm{pattern,} \mathrm{at} \mathrm{the} \mathrm{same} \mathrm{time,} \mathrm{aluminum} \mathrm{carbide} \mathrm{could} \mathrm{not} \mathrm{be} \mathrm{totally} \mathrm{rule} \mathrm{out} \mathrm{from.} \mathrm{According}$ to the result in Fig. 7, the layer of the $\gamma-\mathrm{Al}_{2} \mathrm{O}_{3}$ grew until crystallites of an even denser $\alpha$-oxide started forming at continuously increasing temperature. An accelerated oxidation continued until the oxide layer transformed into a continuous polycrystalline film.

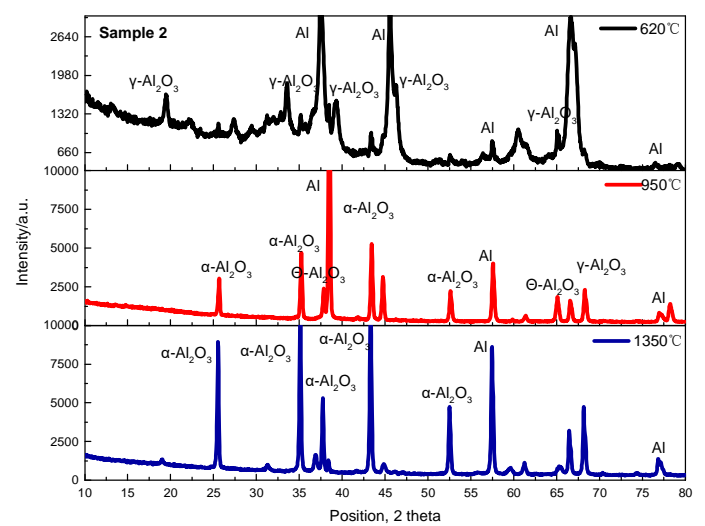

Fig. 7 XRD patterns of $\mathrm{Al} \# 2$ in $\mathrm{CO}_{2}$ environment. 


\section{Oxidation mechanism}

Assuming that alumina was the only solid product in the whole reaction. The mass increasing can be calculated easily according to the chemical reaction equation which should be $88.89 \%$ under ideal condition, however, all the aluminum powders utilized in the experiment consist of impurities. Therefore, even though the active aluminum was oxidized completely, the increasing of mass is less than $87.30 \%$.

Main possible reaction under $\mathrm{CO}_{2}$ heated condition is as follows:

$$
\begin{aligned}
& 2 \mathrm{Al}+3 \mathrm{CO}_{2}=\mathrm{Al}_{2} \mathrm{O}_{3}+3 \mathrm{CO} \\
& 4 \mathrm{Al}+3 \mathrm{CO}_{2}=2 \mathrm{Al}_{2} \mathrm{O}_{3}+3 \mathrm{C} \\
& \mathrm{C}+\mathrm{CO}_{2}=2 \mathrm{CO}
\end{aligned}
$$

Equation 1

Equation 2

Equation 3

DSC curves of reheated sample demonstrated that there was no exothermic peak before the melting point of aluminum, only one endothermic peak $\mathrm{D}$ had been observed which was caused by the melting of aluminum core. The phase of amorphous alumina turned to $\gamma-\mathrm{Al}_{2} \mathrm{O}_{3}$ and certain amount of aluminum was oxidized before $620^{\circ} \mathrm{C}$. Both of the processes had a contribution to restrict the diffusion on both sides of alumina. During the cooling process, crystal structure became much denser. Outwards diffusion of aluminum was limited much more sever by alumina shell. Therefore, no further oxidation happened after the melting point of aluminum. The phase and structure of quenched powders' alumina shell changed, gas diffusion is no longer able to happen easily during the second round of heating. Mass spectrum didn't change which indicate carbon is inside the shell, otherwise, the peak should appear around $1100^{\circ} \mathrm{C}$ as shown before. Fig. 8 is the oxidation process of different sized aluminum particles with the increasing temperature.

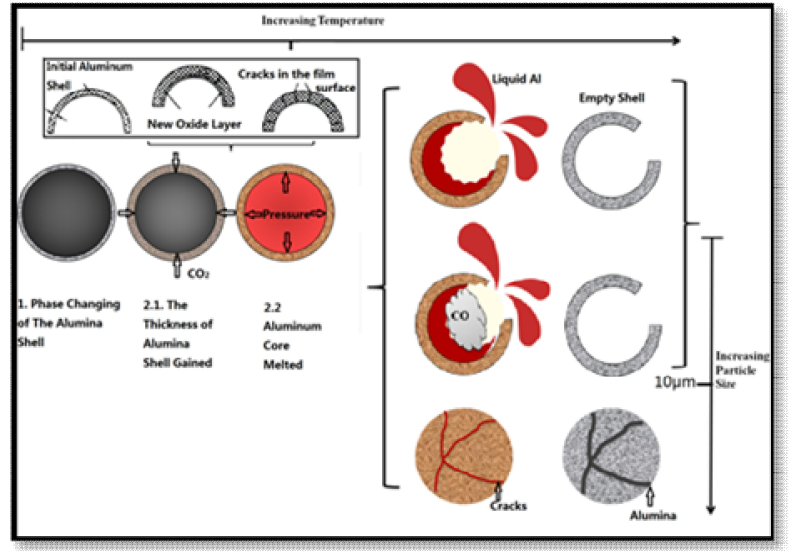

Fig. 8 Sketch map of reaction mechanism of micron-sized aluminum particles.

\section{Thickness of alumina shell}

According to the results of the TG-DSC curves obtained in the first group, the experimental condition was changed appropriately. In order to obtain samples with different thickness of passive alumina layer, micron-sized particles are heated to the end of the first stage ${ }^{14-1514-15}$ which is stand for the increasing of alumina shell in oxidized gas environment then cooled down to room temperature in argon. From the related reference ${ }^{16}$ and the experiment results, the thickness of metal-substrate crystalline-oxide film will increase with the growing of temperature, a significant increase in the metal's reactivity leads to the characteristic change of the protective oxide film. The thickness of the natural amorphous alumina layer which covers the particle surface increases slowly at about $600^{\circ} \mathrm{C}$. Fig. 9 demonstrates the one-time heated TG-DSC curves of original Al\#2 powders from room temperature 
to $1450^{\circ} \mathrm{C}$ and the second round of heated curves in the same temperature range in the reheated process as a representative. Four samples in micro meter range are all restricted in the reheated process. The mass increase is less than 5\% which prove that the particles weren't be oxidized. From the DSC curves in Fig. 9, this process can be further proved. The A, C peaks in DSC curves were disappear and only peak D which stand for the melting of aluminium can be observed clearly.

From SEM images which is show in Fig.6, critical thickness can be measured. When the thickness of the crystalline alumina shell exceeds $10 \mathrm{~nm}$, strong strain effects are evidenced. After being heated to $620^{\circ} \mathrm{C}$ in the first DSC cycle, the thickness of alumina can be measured through SEM images.
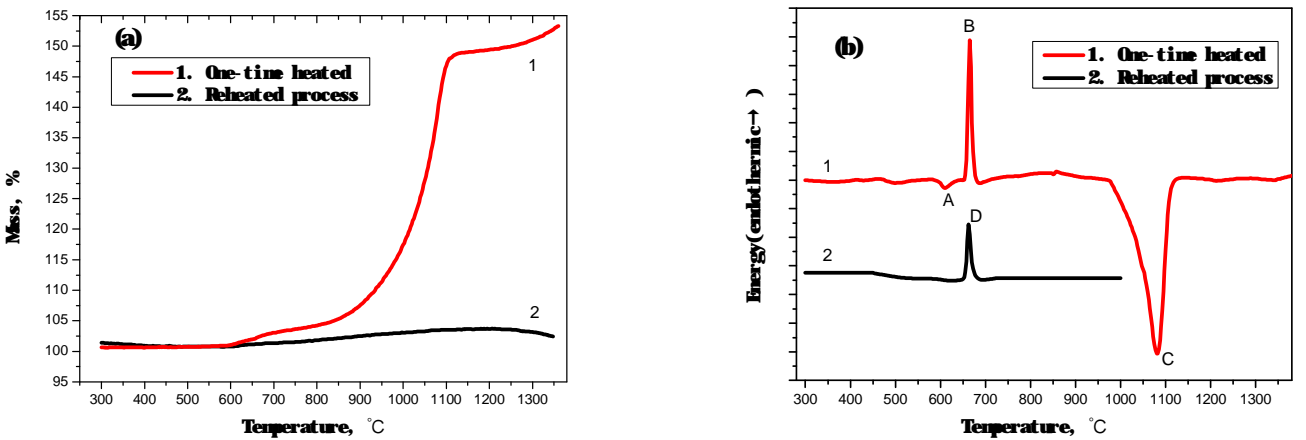

Fig. 9 TG and DSC scanning curves of $\mathrm{Al} 22$ in $\mathrm{CO}_{2}$ one-time heated and reheated process. Comparison of (a) change of mass and (b) heat flow between two heating processes.

\section{CONCLUSIONS}

1. There are four stages during the oxidation There are four stages of the reaction of aluminum powder. The first stage, from room temperature to about $600^{\circ} \mathrm{C}$, alumina aluminum shell phase transition occurs from the initial amorphous transformed into $\gamma-\mathrm{Al}_{2} \mathrm{O}_{3}$. The second stage occurs in the vicinity of $660^{\circ} \mathrm{C}$, alumina, aluminum shell thickness increases while nuclear liquefaction. The third stage, $700^{\circ} \mathrm{C}$ began to about $1050^{\circ} \mathrm{C}$, the liquid aluminum and the environment in an atmosphere of violent reaction. The fourth stage is at the high temperature range to $1050^{\circ} \mathrm{C}$, the phase transformation of alumina to the final product of $\alpha-\mathrm{Al}_{2} \mathrm{O}_{3}$.

2、Gaseous products generated during the oxidation of aluminum particles. The main stage of the oxidation of aluminum powder reaction is more intense in $\mathrm{CO}_{2}$. In contrast, the lower $\mathrm{O}_{2}$ ambient heating slow speed under the second phase of weight gain is relatively slow. The larger the particle size is, the less prone to break the shell response. The generation of carbon monoxide can promote the reaction harder in carbon dioxide environment.

3、After being heated to $620^{\circ} \mathrm{C}$, the thickness of alumina shell increased to more than $10 \mathrm{~nm}$ and the phase change will restrict the further oxidation in gradually heating system.

\section{REFERENCES}

1.Siegert, B.; Comet, M.; Spitzer, D., Safer energetic materials by a nanotechnological approach. Nanoscale 2011, 3 (9), 3534-44.

2.Sippel, T. R.; Son, S. F.; Groven, L. J., Aluminum agglomeration reduction in a composite propellant using tailored A1/PTFE particles. Combustion and Flame 2014, 161 (1), 311-321.

3.Badiola, C.; Gill, R. J.; Dreizin, E. L., Combustion characteristics of micron-sized aluminum particles in oxygenated environments. Combustion and Flame 2011, 158 (10), 2064-2070. 
4.Escot Bocanegra, P.; Davidenko, D.; Sarou-Kanian, V.; Chauveau, C.; Gökalp, I., Experimental and numerical studies on the burning of aluminum micro and nanoparticle clouds in air. Experimental Thermal and Fluid Science 2010, 34 (3), 299-307.

5.Rai, A.; Park, K.; Zhou, L.; Zachariah, M. R., Understanding the mechanism of aluminium nanoparticle oxidation. Combustion Theory and Modelling 2006, 10 (5), 843-859.

6.DREIZIN, E. L., Experimental Study of Stages in Aluminum Particle. 1996.

7.Buckmaster, J.; Jackson, T. L., Modelling the combustion of a sub-micron aluminium particle. Combustion Theory and Modelling 2014, 18 (2), 242-260.

8. Puri, P.; Yang, V. In Thermo-mechanical behavior of nano aluminum particles with oxide layers, 46th AIAA Aerospace Sciences Meeting and Exhibit, Reno, NV, 2008; pp 7-10.

9.Risha, G. A.; Sabourin, J. L.; Yang, V.; Yetter, R. A.; Son, S. F.; Tappan, B. C., Combustion and conversion efficiency of nanoaluminum-water mixtures. Combustion Science and Technology 2008, 180 (12), 2127-2142.

10.Xiaoying Zhu, M. S., Edward L. Dreizin, Oxidation of Aluminum Particles in Mixed CO2H2O Atmospheres. 2010.

11.Aly, Y.; Schoenitz, M.; Dreizin, E. L., Aluminum-Metal Reactive Composites. Combustion Science and Technology 2011, 183 (10), 1107-1132.

12.Rufino, B.; Boulc'h, F.; Coulet, M. V.; Lacroix, G.; Denoyel, R., Influence of particles size on thermal properties of aluminium powder. Acta Materialia 2007, 55 (8), 2815-2827.

13.CRUMP, J. E.; PRENTICE, J. L.; KRAEUTLE, K. J., Role of the Scanning Electron Microscope in the Study of Solid Propellant Combustion: II. Behavior of Metal Additivest $\dagger$. Combustion Science and Technology 1969, 1 (3), 205-223.

14.Trunov, M. A.; Schoenitz, M.; Zhu, X.; Dreizin, E. L., Effect of polymorphic phase transformations in $\mathrm{A} 12 \mathrm{O} 3$ film on oxidation kinetics of aluminum powders. Combustion and Flame 2005, 140 (4), 310 318.

15.Trunov, M. A.; Schoenitz, M.; Dreizin, E. L., Ignition of aluminum powders under different experimental conditions. Propellants, Explosives, Pyrotechnics 2005, 30 (1), 36-43.

16.Jeurgens, L. P. H.; Sloof, W. G.; Tichelaar, F. D.; Mittemeijer, E. J., Thermodynamic stability of amorphous oxide films on metals: Application to aluminum oxide films on aluminum substrates. Physical Review B 2000, 62 (7), 4707-4719. 